\title{
Vivências em um ambiente escolar. significâncias político-pedagógicas de um estágio em atenção primária
}

\section{Experiences in a school environment: political-pedagogical significance of an internship in primary care}

\author{
1 Luiz Eduardo de Almeida luiz.almeida.uffj.edu.br@gmail.com \\ 1 Pedro Aquino Reis de Castro Vitorino \\ 1 Rebeca Ferreira Elerati \\ 1 Robert Wilson da Silva Tostes \\ 1 Sabrina Aparecida de Andrade
}

1 Faculdade de Odontologia da Universidade Federal de Juiz de Fora

\section{Resumo}

Este artigo tem como objetivo analisar as significâncias político-pedagógicas de vivências experimentadas por estagiários de um curso de Odontologia em um ambiente escolar. Trata-se de um estudo qualitativo transversalmente estruturado sob estratégia narrativo-descritiva e moldado à técnica argumentativa. 0 Estágio de Clínica Integrada em Atenção Primária foi didaticamente sistematizado em dois períodos: Pré-intervenção e Intervenção. Do primeiro, se desvendaram duas ações: a contextualização dos acadêmicos estagiários e a estruturação, ambientalização e levantamento de necessidades do ambiente de trabalho. Já o segundo foi guiado pela lógica pedagógica do instrumento TPC (Teorizar-Praticar-Criticar), no qual todas as ações programadas seguiram a lógica ativa do planejamento estratégico, ou seja, contextualizadas às realidades do cenário de prática (ambiente escolar). Conclui-se que, das experimentações vivenciadas algumas inferências se destacaram: a efetividade do instrumento TPC no direcionamento dos acadêmicos estagiários no planejamento estratégico de ações de educação em saúde; o reconhecimento do ambiente escolar como território fértil para o desenvolvimento de atividades promotoras de saúde; a importância de se disseminar, em espaços científicos, os aprendizados advindos de experimentações práticas de estágios.

\section{Palavras-chave}

Promoção da saúde. Educação em saúde. Estágio clínico. Relações comunidade-instituição. Planejamento estratégico.

\section{Abstract}

This article has the function of analyzing the politicalpedagogical significance of experiences by interns from a Dentistry course in a school environment. It is a qualitative study transversally structured under a narrative-descriptive strategy and molded to the argumentative technique. The internship of Integrated Clinic in Primary Care was didactically systematized in two periods: pre-intervention and intervention. From the first, two actions were unveiled, contextualization of trainee academics and structuring, environmentalization and survey of needs in the work environment. The second was guided by the pedagogical logic of the TPC instrument (TheorizePractice-Criticize), in which all programmed actions followed the active logic of strategic planning, that is, contextualized to the realities of the practice scenario (school environment). It is concluded that, from the experience, some inferences were highlighted: the effectiveness of the TPC instrument in directing the trainee academics in the strategic planning of health education actions; the recognition of the school environment as a fertile territory for the development of health-promoting activities; the importance of disseminating, in scientific spaces, the learning from practical experimentation of internships.

\section{Keywords}

Health promotion. Health education. Clinical in internship. Community-institutional relations. Strategic planning.

\section{Como você deve citar?}

ALMEIDA, Luiz Eduardo de et al. Vivências em um ambiente escolar: significâncias político-pedagógicas de um estágio em atenção primária. Cadernos UniFOA, Volta Redonda, n. 42, p. 143-155, abril, 2020. 


\section{INTRODUÇÃO}

Em linhas gerais, pode-se afirmar que a consolidação do processo educacional esbarra na dialética relação entre o pensar e o fazer. Afınal, teoria sem prática se tornaria puro idealismo e abstração, e o contrário se revelaria mero espontaneísmo, pragmatismo (TINTI, 2015).

Refletindo sobre o exposto, pode-se afirmar que práticas educativas que não se esmeram na redução do distanciamento entre o pensar e o fazer se tornam antidialógicas, ou seja, descontextualizadas das condições sociais que a determinam, ou melhor, a justificam.

Sob a mesma lógica, no que tange à reorientação da formação dos profissionais de saúde, a referida interface pensar/fazer se evidencia (ALBUQUERQUE et al., 2008; MADEIRA, 2006). É desse enlaçamento que se dinamiza um indissociável círculo virtuoso, afınal são nos cenários práticos (naturalmente extensionistas) que se dão a socialização do resultado de um fato (pesquisa) e/ou de um aprendizado (ensino) (ALMEIDA, PEREIRA, OLIVEIRA, 2016; ALMEIDA, 2009).

Imbricado ao contexto, os estágios supervisionados emergem como abordagens extramuros fundamentais para o processo formativo dos futuros profissionais de saúde, pois, segundo Bruder et al. $(2017$, p. 297),

\footnotetext{
os estágios supervisionados são considerados espaços no curso de graduação que permitem integrar o aluno ao contexto social e econômico da região de atuação, nos quais são realizados trabalhos que vão desde a educação em saúde até a reversão dos danos causados pelas doenças.
}

Contudo, apesar de seus consolidados benefícios, as atividades desenvolvidas nos estágios, pela frequente atribuição genérica que Ihe é estabelecida, ainda se conflitam com corriqueiras questões, normalmente atreladas à discussões sobre "onde", "como", e "quando" devem ser realizados (MOIMAZ et al., 2016).

A partir de então, imbrica-se uma inquietação: a necessidade de se discutir e, principalmente, de se prover um modelo de ensino pautado nas simbióticas relações entre educação ("o pensar") e trabalho ("o fazer"), ou seja, um processo construído na e para realidade, que é, segundo Almeida (2009), uma premissa que se encerra no reconhecimento da prática como fundamento, critério e finalidade da teoria.

Por fim, atravessado pelo exposto, o presente estudo não apenas se justifica, como alicerçou o seu propósito: analisar os possíveis impactos trazidos pelo Estágio de Clínica Integrada em Atenção Primária/ECIAP junto à qualidade da formação acadêmica do curso de Odontologia da Universidade Federal de Juiz de Fora (UFJF). Para tal, traz um recorte analítico das experimentações político-pedagógicas atreladas ao desenvolvimento de ações educativo-preventivas vivenciadas em um ambiente escolar.

\section{PERCURSO METODOLÓGICO}

Primeiramente, o estudo foi apreciado e aprovado pelo Comitê de Ética e Pesquisa da Universidade Federal de Juiz de Fora (CAAE: 19700619.9.0000.5147 / Parecer: 3.617.647- 03/10/2019).

Trata-se de uma pesquisa qualitativa, estruturada sob estratégia narrativo-descritiva e moldada à técnica argumentativa. Por sua transversalidade, serão aqui referendados os acontecimentos vivenciados no primeiro semestre de 2019 , mais precisamente entre os meses de março a julho. 
Como já exposto, guiado pelos possíveis impactos trazidos pelo ECIAP junto à qualidade da formação acadêmica, o objeto do estudo se delineou na compreensão dos dispositivos político-pedagógicos atrelados às experimentações vivenciadas em um ambiente escolar (Escola Municipal Santana Itatiaia, Juiz de Fora/MG).

Indo além, no tocante aos investigadores, tutores (docentes e odontólogos) e estagiários (acadêmicos do curso de Odontologia - UFJF), merece destacar a fusão de seus papéis, ora observadores ora observados.

É nessa duplicidade de funções que se consagra a observação participativa, pois nela, segundo Creswell (2007, p. 188), "[...] os investigadores identificam explicitamente seus vieses, valores e interesses pessoais [...]". Corroborando, Bell (2008, p.161), reconhece que

a observação participativa não é um método fácil de realizar, ou de analisar, mas apesar dos argumentos de seus
críticos, é um estudo sistemático e disciplinado que, se bem realizado, ajuda muito no entendimento das ações
humanas e traz consigo novas maneiras de encarar o mundo social.

Desse percurso foi direcionada a coleta de dados. Essencialmente narrativo-descritiva, foi instrumentalizada pela utilização dos relatórios das atividades diárias do ECIAP.

Contíguo, seguiu o processo analítico dos fatos. Nesse momento, adentraram-se os elementos argumentativos do estudo, embebidos tanto pelas interpretações de seus sujeitos-autores, quanto pelo confronto junto à literatura científica, o que reforçou ainda mais o papel ativo dos pesquisadores, aqui, descobridores do significado das ações e das relações por eles vividas e percebidas.

De acordo com Minayo et al. (1994, p. 24), "os autores que seguem tal corrente não se preocupam em quantificar, mas, sim, em compreender e explicar a dinâmica das relações sociais que, por sua vez, são depositárias de crenças, valores, atitudes e hábitos".

Enfim, calcada no empoderamento de seus elementos empíricos, esta investigação não se baseou em testar hipótese, pelo contrário, galgou-se aqui uma oportunidade de ofertar a outros leitores um momento de autoanálise, afinal, muitos podem se identificar com determinados aspectos, situações e reflexões.

\section{RESULTADOS EM DISCUSSÃO}

O estágio de Clínica Integrada em Atenção Primária/ECIAP integra, desde 2008, a grade curricular do curso de Odontologia da Universidade Federal de Juiz de Fora (UFJF).

Destinado a acadêmicos do $2^{\circ}$ período, o ECIAP conta com 120 horas de carga horária total, sendo 08 semanais. Contempla a matrícula de até 50 acadêmicos estagiários, equitativamente distribuídos em 02 turmas, A (segunda-feira, das 14 às 18h, e, quarta-feira, das 8 às 12h) e B (quarta-feira, das 8 às $12 \mathrm{~h}, \mathrm{e}$, sexta-feira, das 14 às $18 \mathrm{~h}$ ).

Indo além, na intenção de prover uma melhor relação tutor-estagiário, cada turma foi dividida em cinco frentes de trabalho (Grupos I-A/B, II I-A/B, III I-A/B, IV I-A/B e V I-A/B).

Neste estudo, que integra o processo avaliativo da disciplina, descrevem-se, de forma crítica e reflexiva, as investigações do Grupo V da Turma A, composta por 04 estagiários. 
No que tange ao desenvolvimento de suas ações, de forma a otimizá-las, a lógica do trabalho pedagógico do ECIAP foi, e ainda o é, didaticamente sistematizada em dois períodos, pré-intervenção e intervenção, como mostrado na imagem 1.

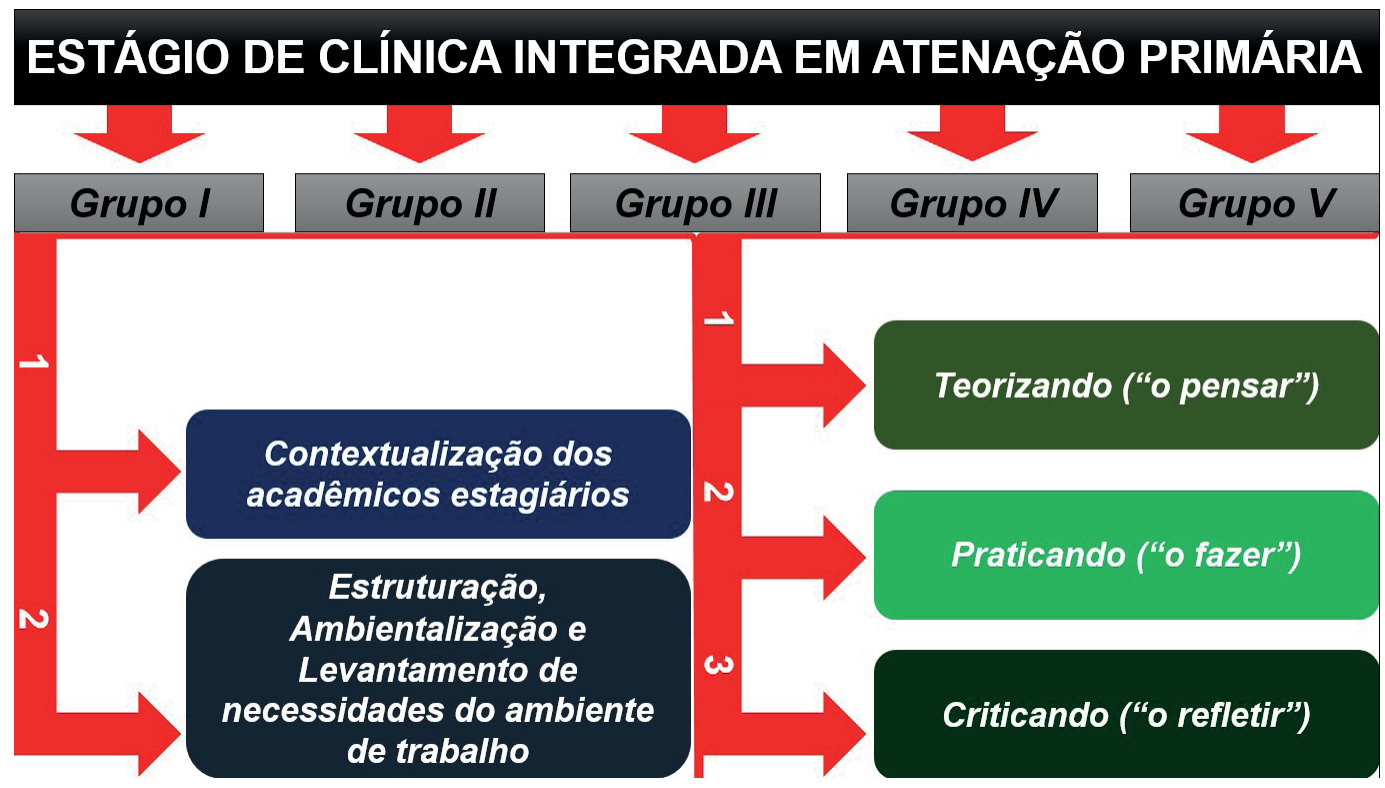

Fonte: autores, 2019.

Do primeiro momento se desvendaram duas ações, a contextualização dos acadêmicos estagiários e a estruturação, ambientalização e levantamento de necessidades do ambiente de trabalho.

Assim, como ponto de partida, coube aos tutores do ECIAP promoverem a imersão científica dos discentes estagiários frente aos seus futuros desafios práticos, ressaltando, neste estudo, a evidenciação do desenvolvimento de atividades de educação em saúde em um ambiente escolar (pré-escolares da Escola Municipal Santana Itatiaia, Juiz de Fora/MG).

Desse ciclo teorizante, se desprenderam dois encontros (18/03 e 25/03/2019), sendo neles abordados os seguintes pontos de discussão: 1. Educação em saúde; 2 . Educação em saúde em interface com a Odontologia; 3. Educação em saúde no ambiente escolar; 4. Planejamento estratégico para o desenvolvimento de ações de educação em saúde.

Nesse ínterim, merecem destaque as técnicas de mediação, que, subsidiadas pelos ideários de diversos estudos, se deram por diferentes estratégias problematizadoras de ensino, destacando aulas expositivas, leitura crítica de artigos científicos, grupos de discussão e oficina para construção de materiais didáticos para educação em saúde (SALIBA et al., 2008; ROCHA et al., 2016; REUL et al., 2016; LAGE et al., 2017).

Seguindo, o período pré-intervenção se encerrou com a estruturação, ambientalização e levantamento de necessidades do ambiente de trabalho. 
Referente à estruturação, a Escola Municipal Santana Itatiaia conta com 10 salas, sendo 05 por turno, matutino e vespertino. Assim, buscando cobertura total desse ambiente, cada grupo de trabaIho do estágio ficou responsável por uma turma de pré-escolares, ou seja, ao Grupo V da Turma A foi direcionada a sala 05 vespertina ( 24 crianças com idade entre 4 e 5 anos).

Quanto à ambientalização, no dia 01/04/2019, a equipe de estagiários realizou uma visita observacional em seu futuro cenário de trabalho. Dessa vistoria buscou-se uma compreensão de como funciona o ambiente escolar, destacando o tamanho da sala de aula, a quantidade e como se agrupam os pré-escolares, seus horários de atividades, onde e de que forma se alimentam, além da avaliação da rotina e da viabilização da higienização bucal das crianças - Imagem 02.

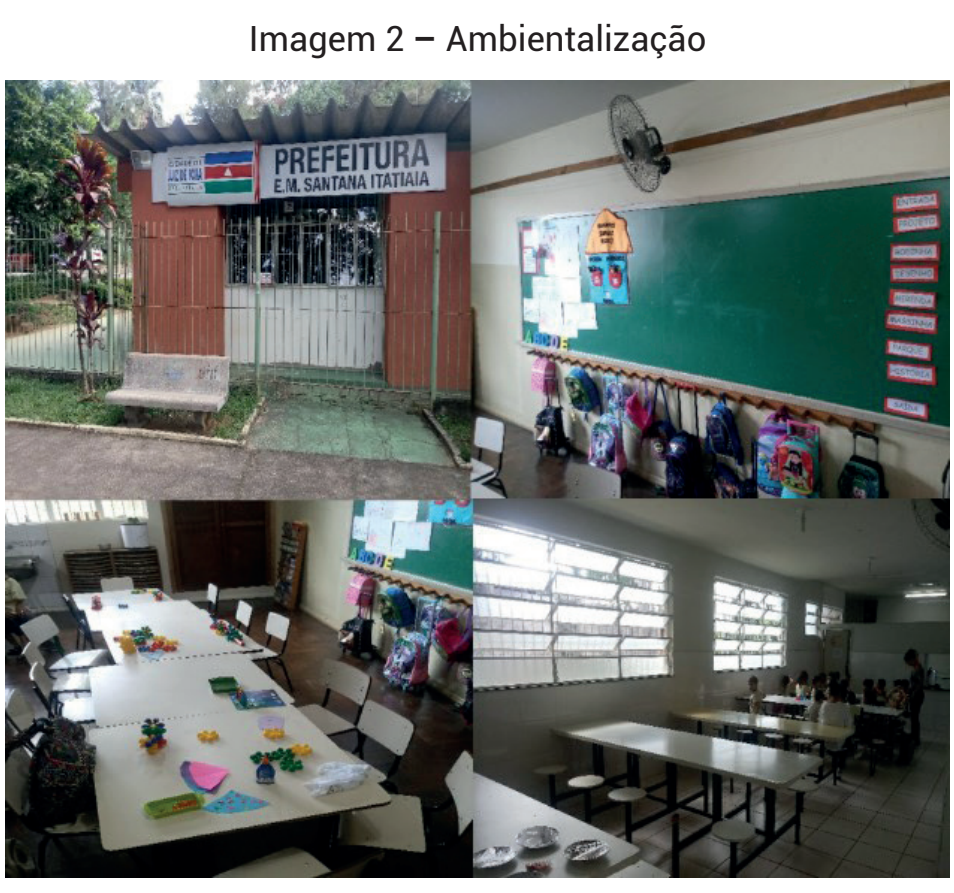

Fonte: autores, 2019

A visita do ambiente escolar se encerrou com o levantamento de necessidades do ambiente de trabalho. Daqui celebrou-se a pactualização das atividades a serem desenvolvidas na escola. Para tal, didaticamente, a equipe de estagiários se dividiu em duas pontas, uma destinada a entrevistar os professores para definirem a temática da ação ("O que vocês gostariam que falássemos?"), e outra a se aproximar das crianças para analisarem os tipos de atividades a serem desenvolvidas ("O que vocês gostam de fazer?").

Após essa sistemática, ficaram definidas a temática e a forma de trabalho, respectivamente, higiene/autocuidado bucal e lucididade.

Até aqui, refletindo um pouco sobre o vivenciado, torna-se fundamental destacar a importância desse momento de escuta, que vai ao encontro aos preceitos educacionais de Freire $(1983,2006,2007)$.

Segundo o educador, a academia deve romper com o ainda frequente movimento de "via de mão única", onde tudo é focado aos ensejos paternalistas da universidade, que vai à sociedade levar algo de sua especialidade, logo, se tornando antidialógica e manipuladora (FREIRE, 1983, 2006, 2007). 
Nesse processo, consumado pela quebra da verticalidade, vislumbra-se os moldes da "via de mão dupla". Assim, sustentada na integralidade da vida humana, a academia não apenas leva informações para a comunidade (ensino), como traz para o cenário universitário vivências (extensão) e dados coletados e interpretados cientificamente (pesquisa).

Contudo, apesar de sua importância, Almeida, Pereira e Oliveira (2016, p.747) reiteram que esse fundamental período de escuta é normalmente burlado pelas ações da academia, consequentemente, "gerando um modelo de trabalho vertical-paternalista, assistencialista e, principalmente, descontextualizado do controle social".

Encerrada a pré-intervenção, abriu-se a intervenção. A partir de então, na intenção de se prover um modelo de trabalho que extrapolasse o apenas "fazer", que também alcançasse "o pensar" e o "refletir", o ECIAP se via afinado às idealizações dos trabalhos de Almeida, Pereira e Oliveira (2016) e Almeida, Pereira e Bara (2009), que materializaram o instrumento TPC (Imagem 3). Segundo os autores,

\footnotetext{
o instrumento apresentado [...] se desenvolve em três etapas: Teorizando ("o pensar"), Praticando ("o fazer") e Criticando ("o refletir"), sendo por isso denominado TPC. Sistematicamente, as etapas se complementam, trazendo em seu bojo conceitual a relação entre planejamento estratégico com a eficácia, eficiência e efetividade de ações de educação em saúde (ALMEIDA, PEREIRA, OLIVEIRA, 2016, p.746).
}

Aqui, tornam-se mister as considerações de Almeida, Pereira e Bara (2009, p.129). De acordo com os estudiosos, o TPC não se consagra como uma "fórmula mágica", pelo contrário, a ferramenta apenas retrata a rica lógica do "ensinar a fazer contextualizado". Além, conforme os mesmos autores, o verdadeiro intuito do instrumento se efetiva na redução do persistente hiato entre teoria e prática, que, consecutivamente, se choca no necessário e desafiante alinhamento dos tempos de trabalho entre serviço e academia.

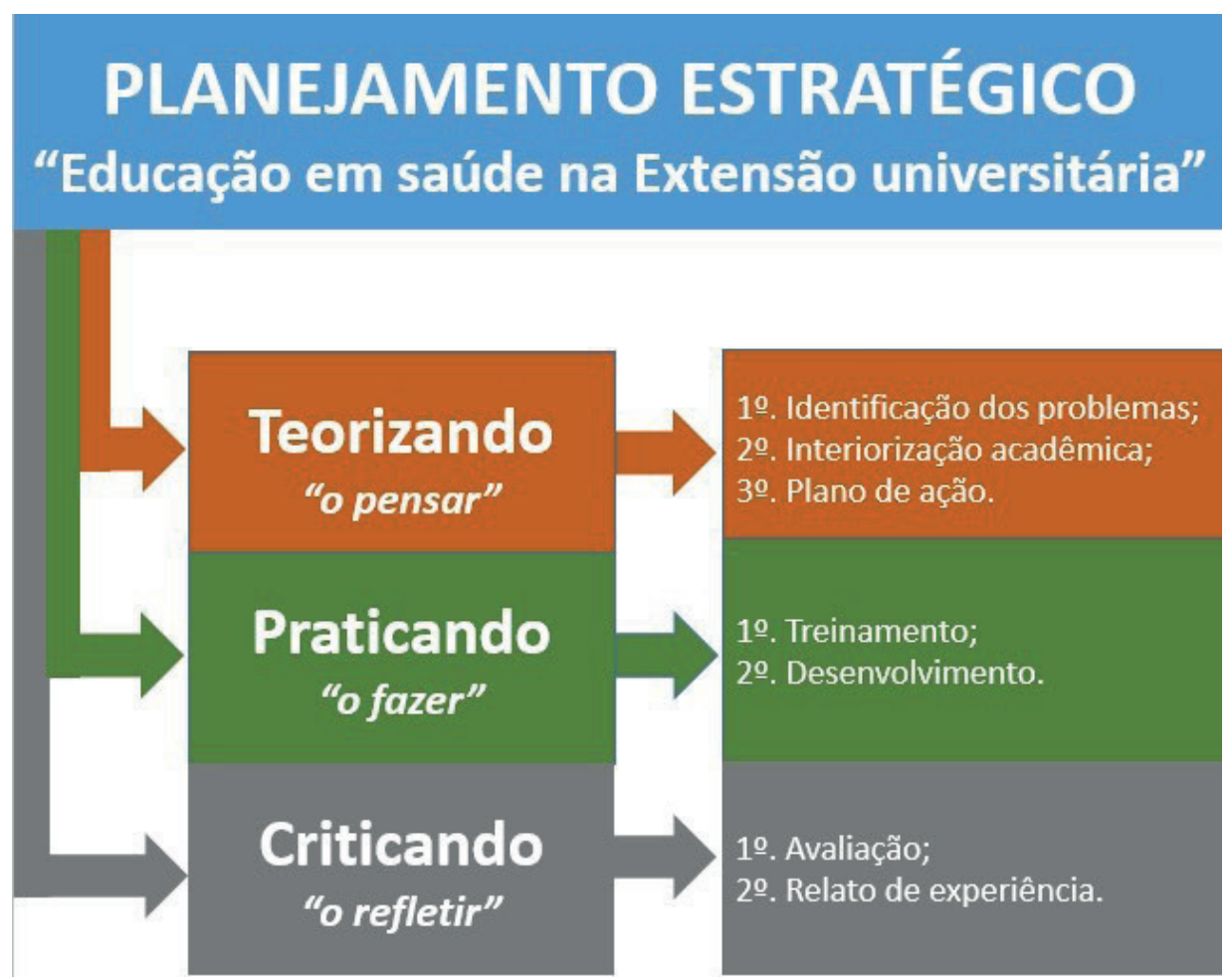

Fonte: ALMEIDA, PEREIRA, OLIVEIRA (2016, p.746) 
Dessa forma, a dinamização da ação de educação em saúde no ambiente escolar foi perpassada pela sistematização do TPC, ou seja, sequenciada em três etapas: "Teorizando/O pensar"; "Praticando/O fazer"; "Criticando/O refletir".

Assim, direcionados pelo instrumento, em 08/04/2019, deu-se o ponto de partida do planejamento estratégico das demandas de trabalho do Grupo V da Turma A, iniciando-se com a identificação do(s) problema(s).

Nesse movimento, apesar da equipe estagiária saber "o que fazer" (desenvolver, aos preceitos da ludicidade, uma ação de educação em saúde junto a pré-escolares abordando a temática higiene/ autocuidado bucal), a equipe se via diante de uma problemática central: "o como fazer?".

Assim, desafiados pelo questionamento, nesse mesmo dia, partiu-se para a interiorização acadêmica. Daqui, foi solicitado aos estagiários o confronto dos ideários teóricos abordados durante a contextualização dos acadêmicos estagiários, com os desafios práticos levantados durante o levantamento de necessidades do ambiente de trabalho.

Em outras palavras, os estagiários perceberam o seu real papel como acadêmicos, o de transformar conhecimento científico em instrumento para se mudar uma realidade.

O encontro foi encerrado com a criação de um plano de ação. Atravessado pelas preconizações da metodologia Brainstorming, a dinamização desse período retoma, através da utilização de um questionário direcionador ("O quê?", "Quem?", "Onde?", "Quando?", "Como?", "Quanto custa?", "Por quê?" e "Como avaliar?") as orientações propostas pela metodologia do instrumento TPC (NÓBREGA, LOPES NETO, SANTOS, 1997; BRAIA, CURRAL, GOMES, 2014; ALMEIDA, PEREIRA, OLIVEIRA, 2016; ALMEIDA, PEREIRA, BARA, 2009).

Após amplo debate e alinhamento de ideias, foi delineado, através da concepção de um mapa conceitual (Quadro 01), o plano de ação do Grupo V da Turma A do "ECIAP" (CARABETTA JÚNIOR, 2013; TAVARES, 2007).

Quadro 1 - Mapa conceitual do Plano de ação do Grupo V/A do ECIAP

\begin{tabular}{|c|l|}
\hline \multicolumn{2}{|c|}{ Plano de ação - Educação em saúde em ambiente escolar - Grupo V/A } \\
\hline Questão direcionadora & \multicolumn{1}{c|}{ Descrição } \\
\hline O quê? & $\begin{array}{l}\text { Desenvolver, aos preceitos da ludicidade, uma ação de educação em saúde junto a pré- } \\
\text { escolares abordando a temática "higiene/autocuidado bucal". }\end{array}$ \\
\hline Quem? & $\begin{array}{l}\text { Público-alvo: } 24 \text { crianças com idade entre 4 e } 5 \text { anos; } \\
\text { Executores: 06 estagiários. }\end{array}$ \\
\hline Onde? & Sala 05 da Escola Municipal Santana Itatiaia, Juiz de Fora/MG \\
\hline Quando? & $\begin{array}{l}\text { Dia: 22/04/2019 } \\
\text { Horário de início: } 14 \text { horas } \\
\text { Previsão de duração da ação: até 30 minutos. }\end{array}$ \\
\hline
\end{tabular}




\begin{tabular}{|c|c|c|}
\hline Como? & $\begin{array}{l}\text { Para a concepção da ação foram progra } \\
\text { Atividade de "Aprendizado" } \\
\text { Nome: "Por que temos que escovar nos } \\
\text { Objetivo: Motivar as crianças assistidas } \\
\text { causa-consequência; } \\
\text { Dinâmica: Construir macromodelos par } \\
\text { dinamizar a relação causa-consequênc } \\
\text { apresentação da boca, mostrar lábios, } \\
\text { indutoras de participação ("Quem tem b } \\
\text { que serve a língua?", "Para que servem } \\
\text { autocuidado, serão utilizadas mais dua } \\
\text { e "O que acontece se não cuidarmos da } \\
\text { oportuno para falar e reforçar a higiene } \\
\text { do dentifrício e do fio dental). Já na seg } \\
\text { através de afixação no macromodelo de } \\
\text { Atividade de "Apreensão" } \\
\text { Nome: "Brincar para reforçar o aprendiz } \\
\text { Objetivo: reforçar e aplicar as informaçã } \\
\text { Dinâmica: Construir um tapete lúdico. N } \\
\text { será a criança pisar no dente coerente à } \\
\text { "Zé Plaquinha", que gosta muito de com } \\
\text { perguntado às crianças como ficarão os } \\
\text { assim, será pedido as crianças para pis } \\
\text { Plaquinha". Para o dia da atividade serã } \\
\text { a outras situaçães. } \\
\text { Atividade de "Desaceleração das crianç } \\
\text { Nome: "Vamos colorir os instrumentos } \\
\text { Objetivo: desacelerar os pré-escolares } \\
\text { rotina da escola; } \\
\text { Dinâmica: levar uma folha para colorir. } \\
\text { se nesta atividade uma retomada das a } \\
\text { Atividade de "Carreamento" } \\
\text { Nome: "Senhores pais/responsáveis, es }\end{array}$ & 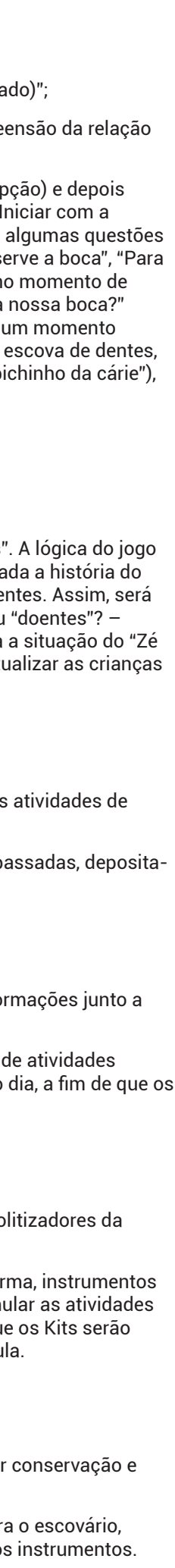 \\
\hline \multirow[t]{5}{*}{ Quanto custa? } & Descrição & Valor (RS) \\
\hline & Material de consumo para dinâmica & 85,00 \\
\hline & Kits de higiene bucal & 0,00 \\
\hline & TOTAL: & 85,00 \\
\hline & \multicolumn{2}{|c|}{$\begin{array}{l}\text { * os kits de higiene bucal foram fornecidos pela Faculdade de Odontologia-UFJF; } \\
\text { ** os valores foram apresentados após a materialização de todos os materiais didáticos } \\
\text { previstos para a atividade. }\end{array}$} \\
\hline
\end{tabular}




\begin{tabular}{|c|l|}
\hline Por quê? & $\begin{array}{l}\text { A justificativa se centrou na valorização da escola como terreno fértil para o } \\
\text { desenvolvimento de atividades de educação em saúde. Além disso, a idade pré-escolar é } \\
\text { um momento da criança fundamental para a construção e consolidação de novos hábitos, } \\
\text { incluindo aí a alimentação saudável e a higiene bucal. }\end{array}$ \\
\hline Como avaliar? & $\begin{array}{l}\text { Avaliação quanti-qualitativa: } \\
\text { Quantitativa: avaliar a cobertura dos assistidos, através da relação entre o número de } \\
\text { crianças presentes e o número de crianças esperadas [Cobertura = (CP/CE)X100]; } \\
\text { Qualitativa: avaliar o grau de adesão dos envolvidos na atividade. }\end{array}$ \\
\hline
\end{tabular}

Fonte: autores, 2019.

Apesar de simples, extraiu-se da etapa de construção do plano de ação uma ferramenta indutora no engajamento dos discentes estagiários junto à solutividades de suas demandas, uma reflexão que embasa o real papel da formação universitária, que não deve se restringir apenas ao fornecimento depositário de conhecimentos para o aluno (aprendizado), pelo contrário, deve aguçar no discente o desejo de aplicá-los (apreensão e carreamento), ou seja, ferramentas transformadoras de uma realidade social.

Além, analisando a lógica educativa utilizada, pode-se afirmar que ela celebra a efetivação do enlace ensino-serviço-comunidade (UFJF-Escola Municipal Santana Itatiaia - pré-escolares), haja vista a concepção das atividades planejadas partirem do contexto social ao qual estão inseridas, ou seja, mais importante que os próprios procedimentos didáticos, é ter consciência e conhecimento do "o quê" e, principalmente, de "para quem" serão ensinados.

Encerrado o estágio observacional (Teorizando/"O pensar"), os estagiários partiram para a etapa "Praticando/O fazer".

O ciclo prático se iniciou com o treinamento. Nesse dia, 15/04/2019, os acadêmicos (Grupo V da turma A) dinamizaram, junto aos professores/tutores, o plano de ação previamente idealizado (Quadro 01), agora, detalhadamente estruturado e materializado. No ensejo, esse processo se destacou nos ajustes e alinhamentos finais nas ações a serem desenvolvidas no ambiente escolar.

Pode-se afirmar que essa etapa teve papel fundamental na preparação da equipe de estagiários. Afinal, ela marca, de forma gradual, a mudança nas funções dos discentes, que se deslocam da condição de observadores/idealizadores para interventores.

Almeida e Oliveira Júnior (2009, p. 64), ainda complementam, "treinar não é eximir-se do erro, pelo contrário, no treino, através da mimetização de uma realidade, vislumbra-se capacitar uma equipe em prover estratégias secundárias para se contornar os tão frequentes e esperados obstáculos da vida real".

Assim, previamente treinados, chega o tão esperado desenvolvimento do plano de ação, em 22/04/2019.

No tocante à dinamização das atividade de "Aprendizado" e "Apreensão" (Quadro 01), em linhas gerias, os resultados alcançados foram exitosos - afinal, percebeu-se a ativa participação dos pré-escolares. Contudo, um ponto a se destacar foi a dificuldade do grupo, em alguns momentos, em controlar a agitação das crianças. Daqui ficou ainda mais evidente a certeza de que o desenvolvimento adequado de atividades de educação em saúde em ambientes escolares é dependente do auxílio dos professores, que nessas situações tornam-se agentes ativos de intermediação e de controle junto aos escolares (Imagem 04). 
Continuando, na intenção de encerrar as atividades, seguiu-se para a desaceleração das crianças. Assim, foi fornecido para cada criança um desenho temático. Enquanto os infantes coloriam suas artes, gradativamente, se via a retomada das professoras como agentes ativos, ou seja, à rotina escolar.

Tão logo, durante a despedida, foram deixados para os escolares Kits de higiene bucal, além de um escovário para acondicioná-los e otimizar seu acesso. Além disso, na intenção de acessar os familiares dos escolares, foi entregue à professora um bilhete para afixar no caderno de atividades extraescolares ("Carreamento").

Para encerrar esse dia, os professores/tutores se reuniram com os estagiários para se iniciar a avaliação da ação desenvolvida (Criticando/"O pensar"). Para tal, centraram-se nos critérios quanti-qualitativos definidos durante a construção do plano de ação, "Como avaliar". Daqui extraiu-se uma cobertura de 95,8\% (01 criança ausente), além do alto grau de adesão dos envolvidos durante o desenvolvimento de todas as atividades programadas.

Imagem 4 - Desenvolvimento do Plano de ação

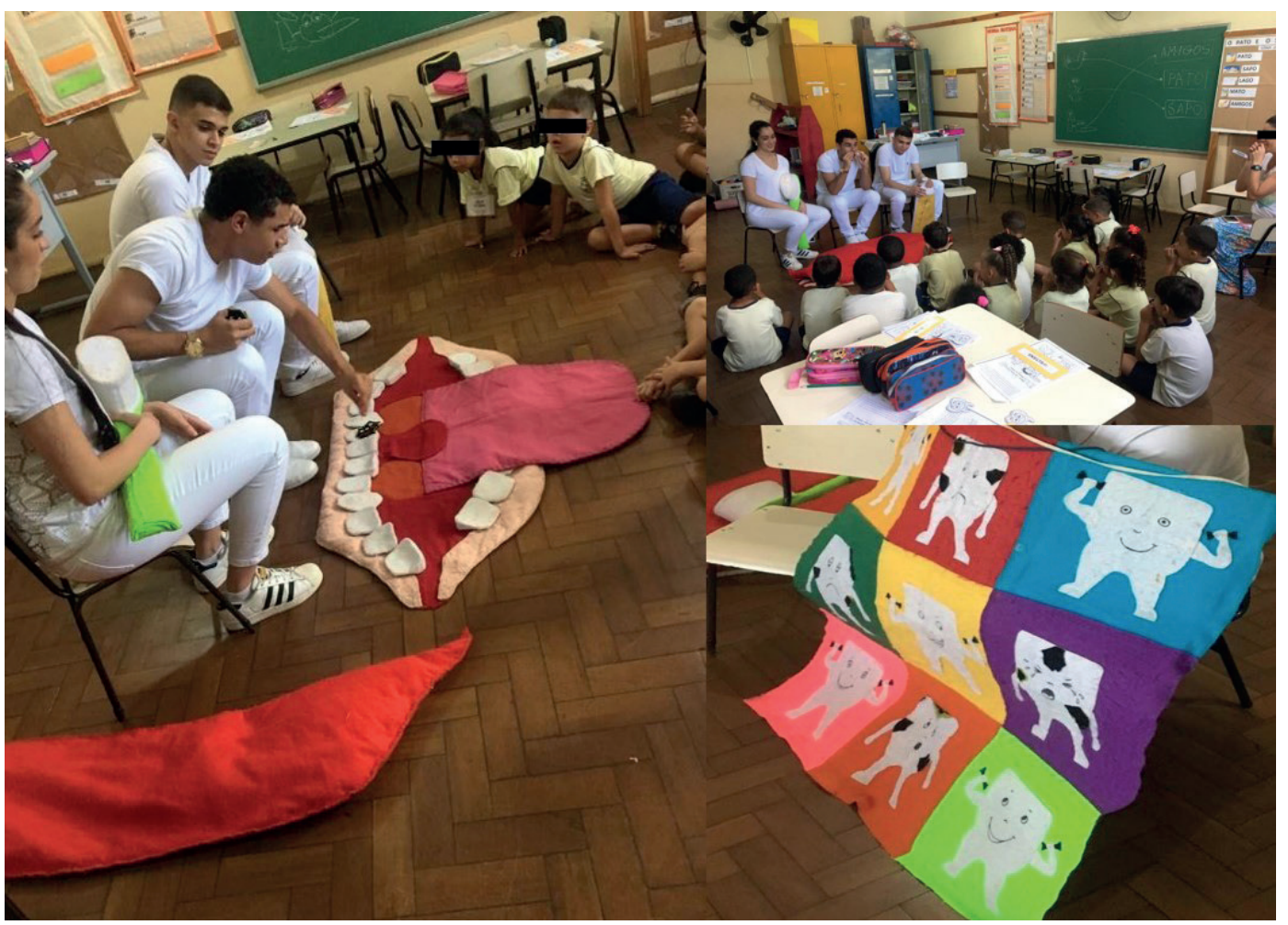

Fonte: autores, 2019.

Adensando um pouco mais, refletindo sobre as experimentações vivenciadas pelo Grupo V/ Turma A, apesar do êxito na execução do plano de ação, ficou evidente o sobrepujamento da realidade prática sobre as expectativas teóricas.

Foi justamente desse confronto entre "teoria/expectativa" e "prática/realidade" que se percebeu o ECIAP como agente ativo no processo de aprendizagem dos estagiários. Afinal, os acadêmicos puderam perceber que suas funções extrapolavam o executar. Deles, foram também exigidas outras habilidades, pautadas na plasticidade do "adaptar", do "criar", do "suprimir", do "postergar", e, principalmente, do "reinventar". 
Assim os discentes tiveram a oportunidade de conhecer o maior desafio de um profissional da saúde: o saber lidar com os desafios e, até mesmo, entraves da realidade, deixando de perceber essas situações como alimento para frustrações, pelo contrário, passando a encará-las como uma oportunidade de melhoramento continuado, percepções que se alicerçam no firmado por Almeida, Pereira e Oliveira (2016, p.747), "uma equipe aprende com os acertos e se transforma com os erros".

Indo além, engendra-se que a teoria não se torna diminuta diante da realidade, pelo contrário, ela ganha forma, sentido, em suma, se justifica.

Nesse prisma, como dito por Rossetti (1999, p.77), "não se deve adaptar os pacientes à ciência, deve-se adaptar a ciência às pessoas". Complementando, o mesmo autor (1999, p.27), "aos doutores, ensiná-los a pensar, não aplicar técnicas ou receitas".

É óbvio que não se poderia esperar, pelo menos em totalidade, a compreensão dos graduandos estagiários das reflexões supradescritas. Por isso a terceira e última etapa do TPC, "Criticando/O refletir", se fundamentou.

Como previsto, o percurso de reflexão se iniciou com a avaliação e se encerrou com a construção do relato de experiência, que integra o processo avaliativo do ECIAP.

De acordo com Almeida, Pereira e Oliveira (2016, p. 747), "entre as diversas metodologias, destaca-se o "relato de experiência", ressaltando que sua construção não deve ser direcionada apenas aos acertos, ou seja, deve-se oferecer espaço também para discutir erros e fragilidades".

Por fim, sob análise global, pode-se afirmar que os cenários práticos ofertados pelos estágios são inesgotáveis para a aplicação dos conceitos disseminados em sala de aula e para o alicerce da pesquisa, em suma, fundamentais para o processo formativo dos futuros cirurgiões-dentistas.

\section{CONSIDERAÇÕES FINAIS}

Após análise detalhada dos dispositivos político-pedagógicos atrelados à dinamização do ECIAP, através das experimentações vivenciadas pelo Grupo IV da Turma A, algumas inferências merecem destaque: o importante papel da modalidade de estágio no processo formativo dos discentes do curso de Odontologia, inserindo-se precocemente em uma perspectiva de trabalho pautada na interface ensino-comunidade; a efetividade do instrumento TPC no direcionamento dos acadêmicos estagiários no planejamento estratégico de atividades de educação em saúde; o reconhecimento do ambiente escolar como território extramuro fértil para o desenvolvimento de ações promotoras de saúde e a importância de se disseminar, em espaços científicos, os aprendizados advindos de experimentações práticas de estágios. 


\section{REFERÊNCIAS}

ALBUQUERQUE, V.S.; GOMES, A.P.; REZENDE, C.H.A.; SAMPAIO, M.X.; DIAS, O.V.; LUGARINHO, R.M.. A integração ensino-serviço no contexto dos processos de mudança na formação superior dos profissionais da saúde. Rev. bras. educ. med, 32(3): 356-362, 2008.

ALMEIDA, L.E. PRÓ-SAÚDE: Ensino, Pesquisa e Extensão. Juiz de Fora: Editar Editora Associada Ltda, 2009.

ALMEIDA, L.E.; OLIVEIRA JÚNIOR, G.I. Sistema de Execução do Projeto. In: Almeida, Luiz Eduardo de (organizador). Pró-Saúde: Ensino, Pesquisa e Extensão. Juiz de Fora: Editar Editora Associada Ltda, 2009, pp.: 63-86.

ALMEIDA, L.E.; PEREIRA, M.N.; BARA, E.F. Projeto de Extensão Sabiá: a introdução de uma prática integralizadora no ensino odontológico. In: Almeida, Luiz Eduardo de (organizador). Pró-Saúde: Ensino, Pesquisa e Extensão. Juiz de Fora: Editar Editora Associada Ltda, 2009, pp.: 126-164.

ALMEIDA, L.E.; PEREIRA, M.N.; OLIVEIRA, V. Governador Valadares (MG) em Extensão: Interfaces para a Dinamização e Instrumentalização do Cenário Extensionista em um Campus Recém-Implantado. Rev. bras. educ. med., 40(4): 743-750, 2016.

BELL, J. Projeto de Pesquisa: guia para pesquisadores iniciantes em educação, saúde e ciências sociais. Porto Alegre: Editora Artmed, 2008.

BRAIA, F.; CURRAL, L.; GOMES, C. Criatividade em contexto organizacional: o impacto de recompensas extrínsecas e do feedback negativo no desempenho criativo. Revista Psicologia, 28(2): 45-62, 2014.

BRUDER, M.V.; LOLLI. L.F.; PALÁCIOS, A.R.; ROCHA, N.B.; VELTRINI, V.C.; GASPARETTO, A.; FUJIMAKI, M. Estágio supervisionado na Odontologia: vivência da promoção da saúde e integração multiprofissional. Rev Bras Promoç Saúde, 30(2): 294-300, 20,17.

CARABETTA JÚNIOR, V. A Utilização de Mapas Conceituais como Recurso Didático para a Construção e Interrelação de Conceitos. Rev. bras. educ. med., 37(3): 441-447, 2013.

CRESWELL, J.W. Projeto de Pesquisa: métodos qualitativo, quantitativo e misto. Porto Alegre: Editora Artmed, 2007.

FREIRE, P. Educação como prática da liberdade. Rio de Janeiro: Paz e Terra. 2007.

FREIRE, P. Extensão ou comunicação?. Rio de Janeiro: Editora Paz e Terra, 1983. Disponível em: http:// www.emater.tche.br/site/arquivos_pdf/teses/Livro_P_Freire_Extensao_ou_Comunicacao.pdf. Acesso em: 22 ago. 2019.

FREIRE, P. Pedagogia da Autonomia: saberes necessários à pratica educativa. Rio de Janeiro: Paz e Terra, 2006.

LAGE, R.H.; ALMEIDA, S.K.T.T.; VASCONCELOS, G.A.N.; ASSAF, A.V.; ROBLES F.R.P. Ensino e Aprendizagem em Odontologia: Análise de Sujeitos e Práticas. Rev. bras. educ. med., 41(1): 22-29, 2017. 
LEME, P.A.T.; PEREIRA, A.C.; MENEGIM, M.C.; MIALHE, F.L. Perspectivas de graduandos em odontologia acerca das experiências na atenção básica para sua formação em saúde. Ciência \& Saúde Coletiva, 20(4):1255-1265, 2015.

MADEIRA, M.C. Ensino, Pesquisa, Extensão. In: Carvalho, Antônio César Perri; Kriger, Léo (organizadores). Educação Odontológica. São Paulo: Editora Artes Médicas, 2006. pp.: 97-103.

MINAYO, M.C.S. Ciência, técnica e arte: o desafio da pesquisa social. In: Pesquisa Social: teoria, método e criatividade / Deslandes, Suely Ferreira (organizadora). Rio de Janeiro: Editora Vozes, 1994. pp.: 0929. Disponível em: http://www.grupodec.net.br/wp-content/uploads/2015/10/Pesquisa_Social.pdf. Acesso em: 22 ago. 2019.

MOIMAZ, S.A.S.; WAKAYAMA, B.; GARBIN, A.J.I.; GARBIN, C.A.S.; SALIBA, N.A. Análise situacional do estágio curricular supervisionado nos cursos de graduação em Odontologia no Brasil: uma questão de interpretação. Revista da ABENO, 16(4): 19-28, 2016.

NÓBREGA, M.M.; LOPES NETO, D.; SANTOS, S.R. Uso da técnica de brainstorming para tomada de decisões na equipe de enfermagem de saúde pública. R. Bras. Enferm., 50(2): 247-256, 1997.

REUL, M.A.; LIMA, E.D.; IRINEU, K.N.; LUCAS, R.S.C.C.; COSTA, E.M.M.B.; MADRUGA, R.C.R. Metodologias ativas de ensino aprendizagem na graduação em Odontologia e a contribuição da monitoria - relato de experiência. Revista da ABENO, 16(2): 62-68, 2016.

ROCHA, J.S.; DIAS, G.F.; CAMPANHA, N.H.; BALDANI, M.H. O uso da aprendizagem baseada em problemas na Odontologia: uma revisão crítica da literatura. Revista da ABENO, 16(1): 25-38, 2016.

ROSSETTI, H. Saúde para a odontologia. São Paulo: Editora Santos, 1999.

SALIBA, N.A.; MOIMAZ, A.S.; CHIARATTO, R.A.; TIANO, A.V.P. A utilização da metodologia PBL em Odontologia: descortinando novas possibilidades ao processo ensino-aprendizagem. Rev. odonto ciênc., 23(4): 392-396, 2008.

TAVARES, R. Construindo mapas conceituais. Ciências \& Cognição, 12(-): 72-85, 2007.

TINTI, E.C. Dilemas entre teoria e prática a partir da formação profissional e das condições objetivas do trabalho cotidiano. In: Capitalismo, trabalho e formação profissional: dilemas do trabalho cotidiano dos assistentes sociais em Ribeirão Preto. São Paulo: Editora UNESP, 2015, pp.: 97-131. 